\title{
Telling different stories, making new realities: The ontological politics of 'addiction' biographies
}

Kiran Pienaar*, Social Studies of Addiction Concepts Research Program, National Drug Research Institute (Melbourne office), Faculty of Health Sciences, Curtin University

Ella Dilkes-Frayne, Social Studies in Health and Medicine Research Program, School of Social Sciences, Monash University,

*Corresponding author contact details: kiran.pienaar@monaśh.edu.

\section{Please cite as follows:}

Pienaar, K. \& Dilkes-Frayne, E. (2017) Telling different stories, making new realities: The ontological politics of 'addiction' biographies. International Journal of Drug Policy, early online. http://dx.doi.org/10.1016/j.drugpo.2017.05.011

Note: This article may not exactly replicate the final version published in the journal. It is not the copy of record. The final published version can be found here: 


\title{
Telling different stories, making new realities: The ontological politics of 'addiction' biographies
}

\begin{abstract}
Personal narratives of alcohol and other drug addiction circulate widely in popular culture and they also have currency in professional therapeutic settings. Despite this, relatively little research has explored the conventions operating in these narratives and how they shape people's experiences and identities. While research in this area often proceeds on the premise that addiction biographies are straightforwardly 'true' accounts, in this paper we draw on the insights of critical alcohol and other drug scholarship, and the concept of 'ontological politics' to argue that biographies produce normative ideas about addiction and those said to be experiencing it. Our analysis compares traditional addiction narratives with the biographies we reconstructed from qualitative interviews with 60 people in Australia who describe themselves as having an 'addiction', 'dependence' or drug 'habit'. We track how addiction is variously enacted in these accounts and comment on the effects of particular enactments. By attending to the ways in which people cope, even thrive, with the kind of consumption that would attract a diagnosis of addiction or dependence, the biographies we produced disrupt the classic narrative of increasing drug use, decline and eventual collapse. Doing so allows for consideration of the benefits of consumption, as well as the ways that people carefully regulate it to minimise harms. It also constitutes individuals as active in managing consumption an important move that challenges dominant understandings of addiction as a disorder of compulsivity. We conclude by considering the implications of our attempt to provide an alternative range of narratives, which resonate with people's diverse experiences.
\end{abstract}

\section{Keywords: addiction biographies; qualitative research; science and} technology studies; ontological politics 


\section{Introduction}

Personal narratives of addiction circulate widely in popular culture. Indeed the media has long been filled with such stories but they often rely on stereotypes and offer few clues about the variety of experiences people have and the many ways they cope and live rich, meaningful lives. Despite the dominance of addiction biographies in popular culture and in some therapeutic settings, relatively little research has explored the norms operating in these accounts and how they shape people's experiences and identities. In this paper we build on the insights of the critical addiction literature to analyse biographies produced as part of a qualitative study of personal experiences of alcohol and other drug addiction in Australia. The biographies were reconstructed from in-depth interviews with 60 people who selfidentified as having an addiction, dependence or habit, and published on a carefully curated, public website [name omitted]. While accounts such as those we developed are often presumed to reflect faithfully 'real-life' experiences, we argue that they produce normative ideas about addiction, with implications for people whose drug use would attract this label. In making this argument we draw on the work of science and technology studies theorists Annemarie Mol (1999) and John Law (2004) to challenge the assumption that it is possible to uncover a pre-existing objective reality of addiction. These scholars argue that there is no stable singular reality that precedes our attempts to know it. Rather, knowledge practices perform what Mol and Law call 'ontological politics'. The concept of ontological politics theorises realities as neither given nor fixed, but shaped within specific practices. The key point of this insight is that we are active in making realities so which ones we make is a political question. In this article, we are concerned with how the practices of reconstructing personal narratives from interviews with people who identify as having an alcohol or other drug addiction, dependence or habit help to make addiction and those who see themselves as affected by it.

In a previous article (Omitted, 2015) we analysed accounts of addiction in two major Australian alcohol and other drug-related websites, arguing that they shape as much as reflect addiction, also shaping individual experiences. We outlined the planned website mentioned above and briefly considered how it might challenge stereotypes and in so doing, help to remake addiction. Here we build on this work to explore in detail how the biographies we produced for the website intervene in the social 
production of addiction. Comparing conventional addiction biographies with our alternative biographies, we spell out the different accounts of addiction and the self they generate. In conducting this comparative analysis, the focus is on how the biographies we produced disrupt the classic addiction narratives of trauma, collapse and redemption that tend to dominate the media and public discourse (Fraser and valentine, 2008). By drawing attention to the agency of those usually depicted as lacking it, and positing agency as a relational achievement, our biographies challenge existing accounts of addiction as a disorder of individual compulsivity. Beyond this, they show how people cope, even thrive, with the kind of consumption that would attract an addiction diagnosis. This emphasis on challenging conventional addiction narratives is not an attempt to dismiss people's struggles or suffering, but rather to draw attention to the ways in which narrating addiction as a disease of compulsivity may actually generate suffering by reinforcing stigma and discrimination.

In the next sections, we provide some background to the Australian alcohol and other drug treatment system, before reviewing the relevant critical social science literature that focusses on addiction (auto)biographies, identifying a need for further work in this area. We then outline our theoretical approach and methods. This is followed by an analysis of traditional addiction autobiographies where we identify their tendency to pathologise and stigmatise regular drug use. Against this backdrop, we then present a range of alternative biographical accounts, which together offer new ways of constituting addiction, or as we will argue, emerge from a different 'ontological politics' than currently operates in dominant accounts of addiction. We conclude by exploring the implications of providing these new narratives.

\section{Background}

Addiction is by no means a simple issue and the term itself is heavily contested. In Australia, the official term in medical and public health circles is 'dependence' (Ministerial Council on Drug Strategy, 2011) and in other contexts, terms such as 'compulsive behaviour' or 'drug problem' dominate. Treatment for alcohol and other drug dependence is delivered via a range of government funded services, including counselling, pharmacotherapy, residential treatment and withdrawal management (Australian Institute of Health and Welfare [AIHW], 2014). Most publicly funded treatment has a harm reduction focus while some is abstinenceoriented and offers interventions in a drug-free setting to assist clients to stop drug use altogether (AIHW, 2014). While Australia's emphasis on harm reduction can be seen as a 
pragmatic and compassionate policy response, in practice treatment modalities underpinned by harm reduction do not always escape the pitfalls of more traditional abstinence-based measures in terms of pathologising illicit drug use and reinforcing addiction stigma (Rance and Treloar, 2013). For example, a body of critical literature has documented the ways in which opioid pharmacotherapy programs in Western liberal democratic countries such as Australia function as mechanisms of social control to discipline those diagnosed with opioid dependence and control their conduct (Fraser, 2006; Fraser and valentine, 2008; Radcliffe and Stevens, 2008; Smith 2010; 2011). Hence these regimented, often punitive, programs reproduce the discredited identity of the 'addict' as lacking self-control and driven by a compulsive attachment to drugs. Consistent with this critique, we suggest that, even in liberal contexts which privilege harm reduction and other medical and public health responses, the repertoire of discourses for articulating regular drug use is limited and often stigmatising.

Moreover, in the Australian context, while harm reduction has gained wide acceptance in treatment and policy domains, the concept has not informed popular culture to the same degree, with mainstream media coverage tending towards a one-dimensional depiction of illicit drug use as a dangerous threat to society, and the source of addiction, crime and deviance (Bright et al., 2007; Warwick Blood, Williams and McCallum, 2003; Fitzgerald, 2015). Perhaps unsurprisingly then, many popular accounts reiterate this all-too-familiar view by characterising addiction as a disastrous state defined by loss of control and harmful drug use (Room, 2003). Personal narratives of addiction, common to both therapeutic and popular contexts, also rely on ideas such as eroded self-control and disordered behaviour. Presented in a revelatory style and often featuring graphic accounts of physical and emotional suffering, these accounts depict addiction as a state of self-destructive excess (Keane, 2001). The narrative trajectory takes a familiar form: increasing consumption, followed by decline and eventual collapse, which then serves as the catalyst for change, usually involving the renunciation of alcohol and other drugs before beginning the upward climb of recovery. While these narratives are most commonly associated with abstinencebased 12-step treatment programs, they also have currency in other treatment approaches and circulate widely in popular culture. Described as conversion narratives, they offer a retelling of past actions from the perspective of a new, 'recovered' identity (Warhol and Michie, 1996). In the process of recounting their story, the narrator constructs a new subjectivity defined by a sense of collective identity with other 'addicts', who are presented as inherently different from 'non-addicts' (McIntosh and McKeganey, 2000). In this way, such 
accounts work to reinforce a series of dichotomies at the heart of disease models of addiction, namely health/disease, normality/pathology and volition/compulsion.

Importantly, however, and counter to the commonly held view that biographies offer a perfect window on reality, we suggest that these biographical accounts do not simply describe a prior reality of addiction. Rather, as Carr (2010) has argued they reference the norms and conceptual logic of 'addiction-as-disease' discourse operating in some therapeutic settings: in adopting the role of the 'recovering addict', clients are socialised to articulate their life story via particular narrative 'scripts'. Individual capacity to present experiences in terms consistent with these normative scripts directly affects access to therapeutic resources and services (Carr, 2010). But these scripts are not only confined to specific treatment contexts, they are all but compulsory in society because of the limited available alternatives for articulating regular, heavy drug use without pathologising it as 'addiction' (Moore, 2008). Indeed, even in the Australian context where harm reduction principles inform policy and practice, many treatment measures operate on the assumption that heavy drug use is inherently problematic and should be reduced or even renounced (Duff, 2008). Like Carr, other scholars working in Western liberal democratic contexts have employed sociological, ethnographic and discourse analytic methods to track the reciprocal relationship between personal narratives of addiction and normative discourses, showing how they rely on each other for meaning (e.g. Andersen, 2015; Fabre, 2016; Keane, 2002; Reinarman, 2005). Weinberg (2000: 606), for example, explores what he calls the 'ecology of addiction' operating in drug treatment discourse. This ecology, he argues, offers clients an addiction narrative that reconciles two competing claims: 1 . They are suffering from a disorder of individual compulsivity, and 2. This disorder can be managed through participation in treatment. Weinberg's analysis draws attention to a central conundrum underpinning the disease model: although addiction is understood to be a disease of the will, marked by loss of control, affected individuals are expected to exercise their will in order to overcome it. So while this model seems to absolve individuals of responsibility for their addictions, in a contradictory reflex, it renders them responsible for their recovery. 
The contradictions operating in addiction discourses are also the focus of Keane's (2001) examination of popular addiction autobiographies. Drawing on three narratives, her analysis traces the ways in which they simultaneously repeat and undermine conventional understandings of addiction as a mental disorder located in the individual. In these personal accounts, the 'disease of addiction' cannot be quarantined from the social and institutional contexts through which it materialises. Yet addiction discourse 'requires that acts be understood not as discrete events emerging from the contexts in which they took place, but as recurrent expressions of a singular ongoing pathology' (Keane, 2001: 568). Importantly for our purposes, Keane directly challenges the view that these accounts present true stories offering unmediated access to the truths of addiction, arguing instead that they can be read as sophisticated productions of identity' (2001: 567). In other words, she disrupts a basic premise of these accounts: that it is possible to uncover a stable prior reality of addiction. As she and other scholars have convincingly argued, addiction is more productively understood as an unstable phenomenon, multiple in its ontologies, and continually made and changed in practice (Fraser, Moore and Keane, 2014; Fraser and Moore, 2011; Keane, 2002).

With this in mind, and returning to the literature, we note that while the abovementioned research makes an important contribution to tracking the social production of addiction in biographical accounts, it leaves open an important question: given the limitations of existing accounts, how might we proceed differently? In addressing this question, we proceed from the premise that addiction is produced through the various ways we define and deal with it (Moore and Fraser, 2013). On this understanding, addiction emerges in part through the interventions designed to address it, that is, as an effect of particular treatment practices and policy measures, rather than a precursor to them. If we accept that addiction is not a pre-existing entity, but is created through our definitions, understandings and responses (Moore and Fraser, 2013), then the possibility emerges that we can define, understand and produce it differently, in ways that might be more beneficial for those living with regular drug use. It is on this basis that we turn to the notion of ontological politics. 


\section{Approach}

To conduct our analysis, we draw on the concept of 'ontological politics' first coined by science and technology studies theorist Annemarie Mol (1999) and later elaborated by Mol's close collaborator John Law $(2004,2009)$. The term refers to an approach that treats materiality as constantly in the making, rather than given in nature and fixed. Underpinning the notion of ontological politics is the recognition that practices, including those associated with research, produce particular realities and prevent others from materialising. The concept has been used to productive effect in recent alcohol and other drug scholarship (e.g. Fraser and Moore, 2011; Keane, Moore and Fraser, 2011; Dwyer and Moore, 2013; Savic and Fomatti, 2016) and in this paper we apply it to theorise the role of our research in remaking addiction via personal narratives.

It is the recognition of the emergent, provisional nature of realities that underscores the transformational value of this theoretical approach: if realities are done in practice, then they can always be done differently. According to Law, thinking in terms of ontological politics 'opens a political space' and encourages consideration of 'how the real might be better enacted', where the term 'enact' expresses the ways in which realities are iteratively performed, rather than merely described or observed from a distance (Law, 2009: 242). Central here is the question of how realities and efforts to know them are related. According to these scholars, knowledge-making practices are constitutive of realities: they produce the realities they seek to apprehend. This understanding invites us to consider which realities we want to strengthen and which we want to challenge through our research. By treating the research process as necessarily implicated in the ontology of its object, this article explores how the very process of composing biographies materialises the kind of consumption they describe and those engaged in it.

\section{Method}

The qualitative research project on which this article is based was designed to gather personal accounts of drug use for presentation on a web-based resource on addiction experiences [Name omitted]. The project is a collaboration with Healthtalk Australia, an Australian research consortium that conducts qualitative research into personal experiences of health and illness. Healthtalk Australia collaborative projects use a research methodology developed by Oxford University's Health Experiences 
Research Group (HERG, 2014). Following this methodology, purposive sampling and in-depth qualitative interviewing were used to collect personal accounts from 60 people who responded to a recruitment flyer that opened with the question: 'Do you consider yourself to have a drug habit, dependence or addiction?' The flyer was circulated through drug treatment services, drug user organisations, community noticeboards and on social media. Those who responded were screened to ensure we recruited participants who reported a pattern of consumption that would qualify them for a diagnosis of 'substance use disorder' or 'dependence syndrome', the terms for 'addiction' in two influential diagnostic instruments, namely the Diagnostic and Statistical Manual (DSM-5) (American Psychiatric Association, 2013) and the International Classification of Diseases (ICD-10) (World Health Organization, 1992). Asked how they would characterise their alcohol and other drug use, respondents either self-identified as experiencing an addiction, dependence or habit or said they recognised their consumption could be labelled in these terms. In response to a follow-up question about what made them describe their consumption in this way, respondents referenced ideas that align with standard addiction diagnostic criteria such as 'a sense of compulsion' to take the drug, 'withdrawal' and 'evidence of tolerance'. ${ }^{1}$ They were identified as eligible to participate if they referenced at least three of the DSM-5 or ICD-10 criteria, which would qualify them for a diagnosis of 'substance use disorder' in DSM-5 nomenclature, or 'dependence syndrome' in ICD10 terms. They were also screened to ensure variation in gender, age, drug type(s), and treatment experiences. All reported ongoing $(n=47)$ or past regular use $(n=13)$ of a range of licit and illicit drugs including alcohol, cannabis, heroin, methamphetamine and prescription and over-the-counter drugs. Demographic details are presented in Appendix 1

The study was approved by [omitted] Human Research Ethics Committee (HR 55/2014). All participants provided informed written consent. Following an openended invitation to 'tell us their story', they were asked about their experiences of living with an alcohol or other drug addiction, including how consumption fits into daily life, managing health and well-being and future plans. While participants had been screened to ensure their experiences were relevant to the study's aims, our interviewing approach aimed to create a context in which participants could share diverse experiences, both those that chime with dominant addiction narratives and those that depart from them. The careful framing of study's aims in the interview 
preamble and consent process, combined with the use of open-ended interview questions and non-judgemental cues throughout the interview aimed to create space for participants to articulate a wide range of experiences, including those that challenge 'ruin-redemption' narratives of addiction and the stereotypes on which they rely. This is especially important in a context dominated by such narratives to the relative exclusion of alternative, less pathologising accounts of regular consumption. Interviews took place in urban and regional Victoria and New South Wales, Australia, and were audio-recorded and transcribed verbatim. To protect participant identities, each was given a pseudonym and all identifying details were removed from the transcripts. In composing the participant biographies, we drew on the de-identified interview transcripts and fieldnotes written after each interview outlining the key points in each person's narrative. Crucially the biographies were checked and approved by participants who chose to review them. Participants were invited to correct any errors and indicate any information they did not want included. Only seven of the 47 participants who opted to review their biography requested any changes, including correcting minor inaccuracies and removing potentially sensitive information.

Consistent with our theoretical approach, the biographies are not intended to be infallible historical documents communicating the 'facts' of a life. Instead they offer a particular enactment of a life gathered from the details of a lengthy interview. Relatedly, we have sought to avoid articulating our participants' experiences as unproblematic representations of a prior reality of addiction as doing so would reify the very concept we are seeking to critique. For example, rather than making the common move of characterising regular, heavy drug use as 'addiction', or labelling those who engage in this kind of consumption as 'addicted', we refer instead to patterns of drug use that would attract a diagnosis of 'addiction' or 'dependence'. In doing so, we signal our awareness of the contingent and contested nature of addiction diagnoses and the concepts on which they rely (see also Dwyer and Fraser, 2016). This framing resonates with our theoretical approach in that we recognise our methodological choices and framings as necessarily political: they can serve to reproduce or complicate assumptions about addiction and those seen as affected by it. 
In composing participant biographies from the interview accounts, we were motivated by an interest in complicating or disrupting commonplace assumptions about addiction. As we go on to show, some of our participants shared this concern in telling their stories. However, as might be expected, given the limited repertoire of discourses for articulating regular drug use without pathologising it as addiction, many participants recounted narratives which, on the face of it, appeared to reproduce the dominant view of addiction as disordered compulsion. However, upon closer reading, their narratives also featured elements that disrupt this view, such as accounts illustrating their capacity for autonomy, agency and choice. In producing biographies from participants' narratives, we sought to remain attentive both to how their narratives reproduced dominant assumptions about addiction and how they complicated or undermined them. This approach is consistent with the concept of ontological politics in that it exposes multiplicity and complexity in practices that appear to be producing a singular, stable reality (Law, 2008; Law, 2009). In other words, we sought to produce biographical accounts that acknowledge, rather than efface, the complexities and contradictions at work in the dominant model of addiction as disordered compulsion. In this respect, the biographies we produced perform a different ontological politics to that currently operating in influential public enactments of addiction. However, insofar as they tell stories of individual experiences, they can be seen as consistent with the humanist genre of the biography. But our accounts also complicate the humanist ontology at the heart of traditional addiction narratives in that they do not assume from the outset that addiction is a 'problem' located in the individual human subject, or indeed that it is a problem at all. Rather, as we go on to show, we recognise that addiction emerges through a complex network of human and non-human forces that include, but far exceed, individual patterns of drug use and assumptions about compulsive disordered subjects.

In the next sections, we compare extracts from traditional addiction narratives with the biographies we produced, asking how they differentially make addiction and those who understand themselves through its lens. The first narrative comes from a website called www.drugfree.org, a US not-for-profit organisation targetting young people and families that provides 'support and guidance [...] on substance use', and includes biographies framed as 'stories of hope' (Drug Free, 2016: www.drugfree.org/stories-of-hope/). It was chosen because it offers a typical 
example of an addiction autobiography, following a narrative trajectory that will be familiar to most readers. The other narratives are drawn from a previous article (Omitted, 2015) analysing the enactment of addiction on two key Australian websites: 1) Reachout (http://au.reachout.com/), a youth-focussed online mental health resource featuring personal accounts of drug use, and 2) Tell your story (www.tellyourstory.org.au/), a website presenting the largest number of personal narratives of drug use of any online Australian resource. On both the US and Australian sites, the narratives are not systematically collected or analysed, and apart from stylistic editing, they are reproduced verbatim. Our method is spelled out in the previous article but to summarise, we extracted the narratives from these websites and searched for key themes across the data to guide our analysis. We then conducted a close discourse analysis of the narrative data, exploring how they enact addiction and the implications of particular enactments for those who see themselves as experiencing it.

\section{Narrating addiction as a disorder of compulsion}

We begin with a classic addiction narrative taken from the US website, drugfree.org: My name is Sofia and I am a recovering addict and alcoholic. I started using when I was 12 years old. What started out as drinking alcohol and smoking weed quickly escalated into regular use of narcotics, and by the age of 13 I was abusing cocaine and prescription pills on a regular basis [...] My life was out of control [...] After an incident in which I threatened to commit suicide, I was forced into a long-term drug treatment program [...] This experience not only changed my life forever - it saved my life [...] Today, I have been clean and sober for nearly seven years.

(Sofia, 2015: www.drugfree.org/stories-of-hope/sofias-story/)

With the deceptively simple opening phrase, reminiscent of the formula used in selfhelp groups such as Alcoholics Anonymous, Sofia defines herself solely in terms of her 'addiction'. What comes into view under the subjectivity of the 'addict/alcoholic' in this account is apparently excessive drug use, severed from its context and the meanings attached to it. Moreover, by describing herself as an 'addict' and 'alcoholic' despite nearly seven years 'clean and sober', Sofia presents addiction as a chronic, incurable condition. Whenever addiction is enacted in these terms, the implication is that the 'recovering addict' identity is inherently unstable, always at risk of 'relapse', 
thus requiring the affected individual to be ever vigilant of the threat of returning to addiction (Neale et al., 2014). In more general terms, the narrative arc of Sofia's account follows what Reinarman (2005: 314) calls the 'ruin-and-redemption' narrative: it involves increasing drug use, decline and eventual collapse, which acts as the catalyst for change. According to this narrative trajectory, the only available option to overcome addiction is to renounce drug use and pursue lifelong abstinence. However, as our research has shown, the requirement to stop drug use altogether is not necessarily feasible or desirable for some people, who may simply be looking to change their patterns of consumption to maximise benefits and minimise potential harms (Omitted, 2016).

We turn now to Australian addiction narratives by drawing on examples from our previous article (Omitted, 2015) analysing addiction discourses on two key Australian websites (details in the method section). In doing so, we observe important continuities in terms of how addiction is constituted in the US-based narrative above and the Australian examples presented next. Notable in many of the personal narratives on the Australian websites is the tendency to present consumption as intrinsically harmful. Typical are descriptions such as the following, which interpret consumption as a sign of deep-seated psychological problems:

- 'By the time I was 13 years of age I had been sexually abused for many years and was so emotionally damaged that I turned to alcohol [...] to block out the pain, the anger and the humiliation' (www.tellyourstory.org.au)

- 'I drank to escape the nightmares of being sexually abused by my mother's boyfriend. I drank to reassure myself that it was ok to stay in an abusive relationship [...] I abused alcohol to avoid what was going on in my life' (http://au.reachout.com) In each of these accounts, alcohol and other drugs provide a way of managing socially constituted problems outside the control of individual subject-sexual abuse and domestic violence. Yet, as with the example from the US website, the narrators locate the cause of these problems in themselves and they interpret their consumption as evidence of a damaged psyche.

Also noteworthy in many of the accounts on the Australian websites is the characterisation of addiction as enslavement to drugs:

- 'in the end my whole life revolved around using' (http://au.reachout.com).

- 'I decided that I was tired of a drug controlling my life' (www.tellyourstory.org.au) 
Consistent with the narrative from the US website, the idea of loss of control figures centrally here, reproducing the association of addiction with disorder and compromised will. Although this understanding is so pervasive as to appear uncontroversial, it can be analysed as a product of a central dualism operating in Western liberal societies - free will and compulsion (Sedgwick, 1993; Valverde, 1998). By valorising the idea of free will, we have produced its opposite: the pathologisation of compulsion (see also Fraser, Moore and Keane, 2014). The point here is that the understanding of addiction referenced in these accounts does not reflect an objective reality, but is produced through specific social norms, notably the idealisation of free will and the denigration of compulsion or dependence. If we accept this, then a key task for critical alcohol and other drug research must be to question commonly held assumptions about addiction and its tethering to compulsion and loss of control. Doing so is important because people are so exposed to these ideas (to the relative exclusion of other, less pathologising understandings of regular drug use) that it is making their experiences in narrow, stigmatising ways.

So if we find these kinds of narrative problematic or limiting, how else might we proceed? How might we articulate regular, heavy drug use in ways that accommodate diverse experiences, especially those that challenge stigmatising assumptions about compulsive, disordered subjects? It is to these questions that we turn next, describing the choices we made in composing participant biographies for presentation on a public website. In comparing the biographies we produced with more conventional narratives we recognise that because the latter are autobiographical they could be read as more authentic, allowing privileged access to the truths of addiction as revealed by real-life experiences. However, this reading reiterates a basic premise of autobiography: that such accounts faithfully reflect an anterior reality, offering a perfect window on true life experiences (Valverde, 2002). But as we noted earlier, this premise is both conceptually and empirically shaky: personal narratives are not infallible documents presenting the 'facts' of a life. Instead they are always socially and culturally constituted and this makes the task of writing them an unavoidably political act. In our case, it carries with it a heightened responsibility to accommodate diverse experiences, without relying on tired tropes that reproduce addiction stigma.

\section{Beyond pathology: Remaking addiction}

A key decision informing the composition of our participant biographies relates to how each account opens. ${ }^{2}$ Consider, for example, the openings to the biographies of 43-year old Bill and 53-year old Helen: 
Bill works part time in retail and enjoys spending time doing outdoor activities with his wife and two children. He goes camping and bush walking, and also enjoys cycling, skateboarding and swimming at the beach. A creative person, he also paints, draws and takes photographs.

Helen has completed a $\mathrm{PhD}$, which involved research overseas, and has written several books. In the past she worked in the health sector. She has a teenage child and describes becoming a mother as 'the best thing [she] ever did'. She's fond of walking, travelling and spending time with her child. Instead of launching straight into an account of drug use, each biography begins by describing the person, what they do, their interests and hobbies, and what is important to them. This simple intervention is an important one in that it avoids reducing people to their experience of drug use or addiction, and presents them instead as people with multifaceted lives, who share recognisable joys, interests and concerns. Doing so is necessary to counter the stigmatising view that people who live under the sign of 'addiction' are dysfunctional, deviant or sick, and thus inherently and irrevocably different from the rest of society (Keane, 2001). Of course, we acknowledge that these accounts, like all biographies, are necessarily selective: they bring certain aspects of people's lives into focus (e.g. family background, occupation, hobbies and interests) and de-emphasise others (e.g. socioeconomic status, appearance, religious background). Our point here is not to imply that the accounts we have produced are somehow 'better' or 'more accurate' than those that focus exclusively, or primarily, on drug use. Rather our aim is to analyse the ontological politics of these biographical accounts in terms of how they articulate the lives of people who see themselves as affected by addiction in ways that are less pathologising and more expansive than traditional addiction narratives allow.

Our concern with combatting stigmatising assumptions is also evident in the language of the biographies, notably in the absence of metaphors and tropes common to traditional 'addiction' narratives, such as 'hitting rock bottom'. Part of the treatment-recovery lexicon, this negatively freighted metaphor articulates addiction as an inexorable descent, a state of affliction in which reaching a point of collapse 
('rock bottom') is a pre-requisite to recovery (Shinebourne and Smith, 2010). In contrast, consider the following extract from 42-year old Emma's biography:

Emma was working full time and feels she wasn't coping with 'being a wife, a mum, and earning money'. She began drinking heavily and taking Xanax, Valium and codeine 'to get through the day without having an anxiety attack'. Emma's husband was very concerned about her and organised for her to go into a seven-day detox. Emma wasn't keen to go and expressed some ambivalence about her experience of detox in that it was a way to escape the anxiety [she] had at home' but when she returned home she still had to cope with it. A few months later she resumed drinking [...] A few years before the interview, Emma reached a point where she felt she 'couldn't cope any more' (emphasis added).

This account acknowledges Emma's struggles without reiterating the metaphor of collapse common to conversion narratives. More than simply a question of semantics, this alternative framing avoids presenting alcohol and other drugs as inherently harmful - as the singular cause of personal decline and destruction. While such essentialising accounts are all too common as the previous narratives illustrate, they neglect the other issues beyond drug use that contribute to everyday struggles and challenges. In Emma's case, her sense of not coping is bound up with her family and work responsibilities and as she explained in the interview, her consumption could be seen as an attempt to manage these responsibilities, rather than the underlying source of her problems.

Another important intervention the biographies perform is to disrupt the binary logic that connects addiction to misery, decline and loss of control. They do so by describing the ways in which people cope, even thrive, with the kind of consumption that would attract a diagnosis of addiction or dependence. The following extract from Helen's biography is illustrative:

In her early twenties, Helen moved interstate to go to university. She says she 'drifted into' a 'population of people' who took heroin and began taking it herself. Heroin, she says, made her 'feel much better about doing' her day-today tasks and 'a bit more inspired' to 'sit and write'. She continued to take it [daily] for several years, while completing her university studies and working overseas. She found that 'money wasn't really a problem' while she was working full time and doing occasional sex work. However, at various times 
over the years, her income was limited and she found it hard to afford heroin. At these times she reduced her consumption by completing residential detox programs, or by moving to places where heroin was less easily available.

In undoing the association of addiction with compromised volition and loss of control, this extract articulates Helen's agency: how she made decisions about her consumption, managing it while completing her studies and working, how she sought treatment to help her cut down to a 'level she can afford'. Helen is constituted in this account not as an irrational 'addict' whose will has been weakened by an attachment to drugs, but as an agentive, choosing subject. Of course, we recognise that pointing out the agency of our participants has mixed strategic merit. On the one hand, it acknowledges the autonomy and self-control of people who identify as experiencing 'addiction'. However, doing so responsibilises individual drug users, making it possible to blame and punish them when they do not achieve the neoliberal ideal of the rational, choosing subject (Moore and Fraser, 2008). Conversely, repeating the stigmatising stereotype that those seen as experiencing addiction lack self-control pathologises them as disordered subjects in need of treatment. This moral-ethical dilemma suggests a need for a different account of agency and individual choice. Responding to this need, we conceive agency and choice not as attributes of individual human subjects, but as distributed phenomena, produced in the encounters of human and non-human forces (Law and Mol, 2008). According to an understanding of agency as distributed, Helen's capacity to manage her consumption is shaped by her income and employment situation, the availability and cost of heroin, opportunities for travel and access to treatment services. Such a rethinking avoids constituting agency as unfettered, acknowledging instead that particular patterns of consumption are a relational achievement, contingent on a complex network of practices that extend beyond the domain of the individual subject. This is important as it enables an account of addiction framed not in terms of moralising judgements of individual compulsion, but rather in terms of the multiplicity of human and non-human forces that produce patterns of consumption our participants identify as addiction.

The extract above also articulates the ways in which heroin use contributes to Helen's life, for example how it helps her complete her day-to-day tasks and improves her concentration. Doing so acknowledges the benefits that some people 
derive from consumption, countering the commonly held view that drug use is intrinsically harmful and will inevitably undermine individual volition. Such a view relies on a conventional, but untenable, formulation of causality: it depicts addiction as the predictable result of drug use and thus treats addictiveness as an inherent property of all illegal drugs, regardless of individual patterns of consumption (Fraser and Moore, 2011).

Finally, the biographies close with a statement about current consumption patterns and plans for the future. The latter varied considerably across our participants and included plans to pursue or maintain abstinence, cut down, confine consumption to particular social events, maintain current consumption levels, or simply 'wait and see' how the future unfolded. Continuing with Helen's example:

Helen says she feels that having 'a habit on heroin' has become 'exhausting'. She now wants to 'cut right back' to a level of consumption she 'can afford' and is 'comfortable with'. Recently she completed a detox and a residential treatment program, during which she resumed taking Suboxone. She now plans to stay on Suboxone, and have heroin only 'every now and then'.

We see that Helen has no desire to give up drug use altogether; rather she intends to cut down to an affordable level, an intention that was expressed by many of our participants. Others, such as Emma, were pursuing abstinence and expressed the view that 'recovery' requires giving up alcohol and other drugs altogether. Still others commented that when their circumstances change, their patterns of consumption do too, making it difficult for them to predict their future consumption habits. By communicating participants' diverse consumption trajectories and future plans, the accounts produced for this study disrupt the traditional narrative arc which privileges the cessation of drug use as the most effective means of addressing a 'drug habit' or 'addiction'. In doing so the biographies we produced avoid reiterating 'sobriety as the necessary condition of personal truth' (Valverde, 2002: 12), that is, as the only way to rediscover the 'true self' thought to have been undermined by the disease of addiction.

Here we begin to see some of the possibilities for presenting varied experiences of regular consumption without pathologising it as addiction. These alternative accounts produce individual consumers as active in navigating their personal circumstances rather than victims of compromised will. Importantly, instead of defining people in terms of their consumption (as 'addicts') the biographies present them as people with rich, full lives who share recognisable joys, hopes, fears and challenges. 


\section{Suffering, trauma and drug use}

One of the risks in critiquing addiction discourse as we attempt to do here is that it can appear to dismiss or minimise suffering and struggles. This, of course, is not our aim. Rather, in narrating lived experiences, we have sought to present these struggles and difficulties in the context of people's lives. Doing so draws attention to the ways in which addiction is bound up with other social and political issues, such as marginalisation, poverty, violence, isolation, stigma and institutional neglect. For example, 58-year old George offers a poignant account of the role of social isolation in what he refers to as his 'alcohol habit':

George lives in a boarding house and describes feeling quite socially isolated. Every day he meets some of the 'old folks' at a nearby café for a cup of coffee and a chat. Then he visits his local primary healthcare service because it offers him 'good company, people [...to] chat with and have a cup of tea, read the newspaper, stay out of the bar'. When the service closes, he goes home, puts the radio on, has 'a few cones' of cannabis and does some painting or drawing. In the evening when the night stretches ahead of him, George says the 'alcohol habit hits' and he thinks: 'What am I going to do tonight? I don't watch TV, there is only so much radio you can listen to, so many drawings you can do [...] And the next minute, I'm getting together seven bucks to buy a cheap bottle'. He describes the alcohol habit as a 'daily ritual created by [his] isolation'.

The narrative of 48-year old Phoenix is also illustrative of how addiction emerges not just through individual patterns of consumption, but importantly also through suffering associated with violence, family problems, homelessness and physical injury.

Phoenix says he grew up in a 'violent home' and that his parents were 'alcoholics'. He began drinking regularly after leaving home in his mid-teens when his parents separated. He says he supported himself financially during high school by 'thieving', for which he was later arrested and given a custodial sentence of several months. After his release he moved to another city and began working in the construction industry. At the time he says he "drank fairly well all day, every day' [...] A year or so later Phoenix had a motorcycle accident and broke his back. To treat the pain associated with the injury, he was prescribed Panadeine Forte (a combination of paracetamol and codeine) 
but says he began drinking alcohol because he found it more effective for relieving the pain than the prescribed medication.

Many of the issues George and Phoenix reference in their accounts are socially constituted, not readily captured by notions of individual control. By isolating alcohol and other drug use from its social context (or referencing context only in perfunctory ways), therapeutic addiction discourse displaces from view the social and structural factors that contribute to the harms otherwise ascribed solely to consumption. One effect of this individualising impulse is to render the individual responsible for socialstructural issues that warrant attention in their own right, rather than being treated simply as consequences of individual drug use (valentine and Fraser, 2008). This formulation locates pathology in individual subjects, allowing them to become the target of therapeutic discourse and eliding the varied social forces that co-produce health and illness (Germov, 2014). If we accept the social character of health, it becomes necessary to acknowledge the limits of treatment measures directed at individuals. In the context of this research, it entails recognising that the responsibilising therapeutic injunction to reduce or stop consumption would not by itself alleviate the suffering George and Phoenix recount (indeed it may even intensify it given that consuming their preferred drug reportedly helps them cope with their daily struggles). Guided by this recognition, the biographies articulate the impact of trauma, isolation, injury and violence without insisting that experiences of drug use are mechanistically determined by it. This is part of an effort to attend to the social and structural factors imbricated in the phenomena our participants identify as 'addiction'.

\section{Articulating pleasures and benefits}

While the biographies communicate the struggles and difficulties people face, they do so without eclipsing or discounting the pleasures and benefits of drug use. Consider, for example, this extract from 32-year old Dean's biography:

Dean (32) began taking ice [methamphetamine] and GHB in his early twenties, primarily with sexual partners. He says ice reduced his 'inhibitions' and gave him 'a lot more energy' and a 'sense of empowerment'. He also took GHB as 'an expansion' on ice as he says their effects 'complement each other quite well'. 
After about two years of regular ice consumption, Dean began to feel that he was experiencing an 'addiction' to it [...] However, he still found ice 'appealing' and continued to take it and GHB regularly for the next few years.

We recognise, of course, that drawing attention to the role of pleasure risks entrenching the damaging stereotype that people who use drugs are driven by compulsive desires and the pursuit of illusory gratification (valentine and Fraser, 2008). In an effort to disrupt the equation of drug-related pleasure with compromised volition or passive indulgence, we took care to articulate participants' capacity for agency, albeit always contingent on their personal circumstances. Helen's biography quoted above offers one example of this, as does the following extract from the conclusion to Dean's biography:

Dean now takes ice [methamphetamine] 'close to daily' and GHB once or twice a week, mostly in sexual situations. He manages his consumption by going to CMA [Crystal Meth Anonymous] meetings and 'making sure' that he's 'living a life that [he]'s happy living', 'in line with [his] values'. Because he works part time, he limits his consumption to the weekend when he has 'time to [him]self', making sure that he allows a few days break between taking ice and going to work. Ultimately, he thinks it might be best for him to stop altogether because he feels it's become a financial and emotional 'drain on the life that [he] would like to have'. He says he's now focused on maintaining his health and having a good relationship with his family.

Against the commonplace view that people experiencing addiction are powerless to resist drug use, continuing to take drugs despite knowledge of adverse effects, Dean and others emphasised how they regulate their consumption, actively managing the possible risks of heavy use and looking after their health. We are not suggesting here that Dean's capacity to manage his consumption is solely his prerogative; instead in sketching the context of consumption, we see that it is contingent on his employment situation, financial resources, access to a self-help support group, the separation of work and leisure time, his living arrangements (which allow him 'time to himself'), the availability of drugs, and their financial and emotional cost. This account of agency as distributed enacts a different model of personhood from that of popular addiction discourse. Confounding the binary logic central to disease models of addiction, the biographies constitute the research participants as agentive, 
thoughtful consumers rather than passive, irrational victims of the 'disease of addiction'. Crucially, this is not merely our intervention, but one that several participants themselves made in a determined effort to combat stigmatising misconceptions and assert the possibility of alternative narratives. For example, as 33-year old Zadie noted: 'People [who] know me know that I'm extremely together: I'm articulate, I'm really motivated, I'm organised, I achieve what I want to achieve [...] You know, it's possible that you can be completely together and happy, and a great parent, and have a good life, and a job, and all of those things, and inject heroin'.

Our attention to the benefits many of our participants report experiencing from alcohol and other drug consumption arises out of the recognition that focussing exclusively on misery and pain, and uncritically repeating the ruin-redemption account, offers only a partial picture of people's lives. It also retains disease and pathology as the defining features of addiction. But as the following example from 50-year old Rachel attempts to articulate, regular drug use can support health and well-being, rather than threatening only to diminish it:

Rachel met her current partner when she was in her mid-thirties and they began taking heroin together [...] After some time Rachel says she felt 'physically dependent' on heroin and would get 'really crook' if she didn't take it. In her late thirties, she became pregnant and started opioid pharmacotherapy treatment (methadone maintenance treatment [MMT]). After she had her child, Rachel returned to work, resumed taking heroin, and remained on MMT.

In the years before the interview, Rachel has been working full time to support her partner and child. She now limits her heroin consumption to a few days a weeks after work for 'fun' and 'to relax', as she says this contributes to her 'mental health'. In the future, she plans to stay on MMT as it helps her manage her heroin consumption.

Rachel is constituted here not as an irrational, drug-seeking 'addict' whose will has weakened by an attachment to drugs, but as a considered, choosing consumer who carefully regulates her heroin consumption to enjoy the benefits it offers her without it disrupting other aspects of her life. To reiterate the point made earlier, we conceive Rachel's capacity for agency and choice as distributed: it is shaped by reliable 
access to treatment, her employment situation, family responsibilities and being the breadwinner, finances, the separation of work and leisure time and, of course, the availability and cost of heroin. Such a rethinking avoids locating culpability for 'addiction' unfairly and simplistically in the actions (or inaction) of individual human subjects, and allows us to attend more carefully to the network of practices and relations through which particular consumption patterns emerge and change.

As we have shown, the process of composing biographies for presentation on a public website offers a way of intervening in the social production of addiction. The biographies quoted here remind us that the phenomena our participants identify as 'addiction' are variously forged in encounters with other social issues, including marginalisation, trauma, violence, stigma and institutional neglect, but also in the pleasures of socialising and leisure activities, good health and a satisfying life. In producing participant biographies, then, it is important to present the experiences people nominate as addiction as inseparable from other social, cultural and institutional phenomena. More fundamentally, our participants' lived experiences raise acute questions about the ontology of addiction and its value as a way of explaining individual conduct. If addiction can emerge through the pleasures of socialising and a satisfying life, as much as through pain and suffering, then what exactly is addiction? Or to put this slightly differently, given that people can experience regular drug use as 'functional' and as 'problematic' while seeing themselves as addressed by the term addiction, it would seem that pathology is not the self-evident hallmark of addiction promoted by the disease model. Indeed, when applied to the lived experiences recounted in our study, we find that the concept makes little explanatory sense. This suggests the need for careful reflection on how else we can conceive the diverse issues that have come to be gathered under its ever-widening rubric.

\section{Conclusion}

Where much alcohol and other drug research takes for granted the status of addiction as a pre-existing problem that precedes our actions, we have sought to draw attention to the ways in which addiction takes shape through our attempts to understand it and, importantly for our purposes, through the process of narrating lived experiences. In developing the personal narratives for publication on a website, our aim has been to give voice to a diverse range of experiences that exceed the stereotypical 'ruin-redemption' accounts prominent in popular and therapeutic discourses. While acknowledging that some people, including some of the participants in this study, may find it useful to articulate their experiences via these 
discourses, we argue that such discourses work to pathologise regular, heavy drug consumption and thus offer little scope for attending to the ways in which people cope, even flourish, with this kind of consumption. In contrast, the biographies we produced articulate participants' strengths and capacities: they suggest that people who self-identify as having an 'addiction' actively manage their consumption, organising it around everyday commitments and responsibilities, or in response to daily demands and pressures. And unlike traditional addiction narratives that treat regular drug use as inimical to health, these alternative accounts attend to the ways in which it can, for different people and under varying conditions, actually support health and well-being (Omitted, in press). Importantly, the biographies we produced are carefully based on in-depth interviews with people who identified as experiencing addiction, and have been vetted by those participants who opted to review them. In attending to the varied experiences our participants nominate as 'addiction', it becomes evident that the accounts dominating popular and therapeutic discourses participate in a narrow and stigmatising ontological politics. Presenting alternative narratives allows a more expansive, generous ontological politics, one that avoids the pathologising reflex of 'ruin-redemption' accounts and legitimises a wider range of subjectivities for those who live with regular consumption. This is important because as long as addiction is reified as disordered compulsion, those positioned as 'addicts' will continue to be pathologised and stigmatised. Indeed, as we have argued elsewhere, the harms all too readily ascribed to regular alcohol and other drug consumption are at least in part the effect of the disease model of addiction and the stigma generated whenever individual conduct is labelled the effect of disease (Omitted, 2016). In sum, our participants' incredibly diverse experiences raise pointed questions about the ontology of addiction and its usefulness as an explanatory concept. A key part of recognising that addiction can be remade through this research is making its outcomes widely accessible to diverse audiences in an effort to enrich public understandings of life with regular drug use. Our hope is that by presenting these alternative narratives on a public website, we might prompt site visitors to reassess their assumptions about addiction, perhaps even asking themselves how useful the concept is in articulating people's varied experiences.

\section{Notes}




\footnotetext{
${ }^{1}$ While these criteria are generally considered objective measures of pathology, they are context dependent, and rely on the assessment of self-reported behaviour and culturally specific social norms (Dwyer and Fraser, 2016).

${ }^{2}$ Due to space constraints, short extracts from the biographies are reproduced here but the full versions can be found on [website name omitted].
}

\section{Acknowledgments}

The research reported in this paper was conducted in the Social Studies of Addiction Concepts (SSAC) Research Program, based in the National Drug Research Institute, Faculty of Health Sciences, Curtin University, in collaboration with Healthtalk Australia, Monash University, the University of New South Wales' Centre for Social Research in Health and the Hunter New England Local Health District. The research was funded by the Australian Research Council (Discovery Project DP140100996). Suzanne Fraser was funded by an Australian Research Council Future Fellowship (FT120100215). The National Drug Research Institute is supported by funding from the Australian Government under the Substance Misuse Prevention and Service Improvement Grants Fund. The Centre for Social Research in Health is supported by a grant from the Australian Department of Health. Interviews were conducted by Kiran Pienaar, Ella Dilkes-Frayne, Jeanne Ellard and Jamee Newland. The authors extend sincere thanks to the interview participants for generously sharing their stories. 
Appendix: Participant characteristics $(\mathrm{N}=60)$

\begin{tabular}{|l|l|}
\hline Gender^ & Number \\
\hline Men & 35 \\
Women & 25 \\
\hline Main preferred drug ${ }^{*}$ & \\
\hline Alcohol & 11 \\
Cannabis & 14 \\
Opiates & 14 \\
Stimulants & 12 \\
'Party drugs' (e.g. MDMA, GHB, Ketamine) & 4 \\
Prescription and over-the-counter drugs & 5 \\
\hline Age & \\
\hline 18-29 & 14 \\
30-39 & 20 \\
40-49 & 14 \\
\hline 50+ & 12 \\
\hline Cultural and ethnic background & \\
\hline Australian & 31 \\
Australian Aboriginal & 2 \\
New Zealander & 1 \\
Polynesian & 2 \\
North-West European & 12 \\
Southern and Eastern European & 4 \\
North African and Middle Eastern & 1 \\
South-East Asian & 1 \\
North-East Asian & 2 \\
North American & 2 \\
Southern and Eastern African & 2 \\
\hline Sexual identity & \\
\hline Heterosexual & 41 \\
LGBTIQ+ & 18 \\
\hline Unspecified & 1 \\
\hline Education level & \\
\hline Secondary & 26 \\
Post-secondary & 12 \\
Tertiary & 22 \\
\hline Employment status & 41 \\
\hline Working/studying & 19 \\
Not working/studying & \\
\hline Location & 21 \\
\hline Major urban - Victoria: Melbourne & 11 \\
\hline Regional - Victoria: Bendigo & \\
\hline Major urban - New South Wales: Sydney & \\
\hline Regional - New South Wales: Byron Bay, Lismore \& Nimbin \\
\hline
\end{tabular}

$\wedge$ All participants identified either as male or female.

* Some participants reported consuming only one drug, while others talked about two or more. The table lists the drug that participants identified as their primary preferred drug.

$\sim$ Reporting of cultural and ethnic background follows the Australian Standard Classification of Cultural and Ethnic Groups, developed by the Australian Bureau of Statistics. Cultural and ethnic background was classified according to a combination of self-reported group identification with particular cultural or ethnic groups, the participant's birthplace and their parents' birthplaces. 


\section{References}

American Psychiatric Association. (2013). Diagnostic and Statistical Manual of Mental Disorders, Fifth Edition. Washington DC: American Psychiatric Press.

Andersen, D. (2015). Stories of change in drug treatment: a narrative analysis of 'whats' and 'hows' in institutional storytelling. Sociology of Health and IIIness 37(5), 668-682.

Australian Institute of Health and Welfare (AIHW). (2014). Alcohol and other drug treatment services in Australia 2012-13. Drug treatment series 24, Cat. no. HSE 150. Canberra: AlHW.

Bright, S.J., Marsh, A. Smith, L.M. \& Bishop, B. (2007). What can we say about substance use? Dominant discourses and narratives emergent from Australian media. Addiction Research \& Theory, 16(2): 135-148.

Carr, E.S. (2010). Scripting addiction: The politics of therapeutic talk and American sobriety. Princeton: Princeton University Press.

Duff, C. (2008). Governing drug use otherwise: For an ethics of care. Journal of Sociology 51(1): 81-96.

Dwyer, R. \& Fraser, S. (2016). Making addictions in standardised screening and diagnostic tools. Health Sociology Review, 25(3), 223-239.

Dwyer, R., \& Moore, D. (2013). Enacting multiple methamphetamines: The ontological politics of public discourse and consumer accounts of a drug and its effects. International Journal of Drug Policy, 24(3), 203-211.

Fabre, C. (2016). Ideological tropes of contemporary addiction narratives.

Challenging addiction in Canadian literature and classrooms (pp. 25-49).

Toronto: University of Toronto Press.

Fitzgerald, J. (2015). Syringes, metonymy, global fear and news. In Framing Drug Use: Bodies, Space, Economy and Crime (pp. 30-54). Basingstoke/New York: Palgrave Macmillan. 
Fraser, S. (2006). The chronotope of the queue: Methadone maintenance treatment and the production of time, space and subjects. International Journal of Drug Policy 17(3): 192-202.

Fraser, S. \& valentine, k. (2008). Substance and Substitution: Methadone Subjects in Liberal societies. Basingstoke: Palgrave Macmillan.

Fraser, S. \& Moore, D. (2011). The drug effect: Constructing drugs and addiction. In Fraser, S. and Moore, D. (eds) The Drug Effect: Health, Crime and Society (pp. 1-16). Cambridge University Press, Melbourne.

Fraser, S., Moore, D. \& Keane, H. (2014). Habits: Remaking addiction. Basingstoke and New York: Palgrave Macmillan.

Germov, J.B. (2014). Second opinion: An introduction to health sociology (5th ed.). Melbourne: Oxford University Press.

Health Experiences Research Group (HERG). (2014). Researcher's handbook for producing HealthTalkOnline and YouthHealthTalk websites. Health Experiences Research Group, Oxford University: Oxford.

Keane, H. (2001). Public and private practices: addiction autobiography and its contradictions. Contemporary Drug Problems 28, 567-594.

Keane, H. (2002). What's Wrong with Addiction? Melbourne: Melbourne University Press.

Keane, H., Moore, D., \& Fraser, S. (2011). Addiction and dependence: making realities in the DSM. Addiction, 106(5), 875-877.

Law, J. (2004) After Method: Mess in Social Science Research. London: Routledge.

Law, J. (2008), On sociology and STS. The Sociological Review, 56: 623-649.

Law, J. (2009). The Materials of STS', version of 9th April 2009, available at http://hwww.heterogeneities.net/publications/Law2008MaterialsofSTS.pdf [accessed 11 April 2017].

Law, J. (2009). Seeing like a survey. Cultural Sociology 3, 239-256. 
Law, J. \& Mol, A. (2008). The actor-enacted: Cumbrian sheep in 2001. In L. Malafouris \& C. Knappett (eds). Material Agency: Towards a NonAnthropocentric Approach (pp. 57-77). New York: Springer.

McIntosh, J. \& McKeganey, N. (2000). Addicts' narratives of recovery from drug use: constructing a non-addict identity. Social Science \& Medicine, 50(10), 1501-1510.

Ministerial Council on Drug Strategy. (2011). National drug strategy (2010-2015). Canberra, Australia: Ministerial Council on Drug Strategy. Available at: http://www.nationaldrugstrategy.gov.au/internet/drugstrategy/publishing.nsf/ Content/DB4076D49F13309FCA257854007BAF30/\$File/nds2015.pdf [accessed 11 January 2017].

Mol, A. (1999) Ontological Politics. A Word and Some Questions. The Sociological Review $46,74-89$.

Moore, D. (2008). Erasing pleasure from public discourse on illicit drugs: On the creation and reproduction of an absence. International Journal of Drug Policy, 19(5), 353-358.

Moore, D. \& Fraser, S. (2008) Putting at risk what we know: Reflecting on the drugusing subject in harm reduction and its political implications. Social Science and Medicine, 62(12), 3035-3047.

Moore, D. \& Fraser, S. (2013). Producing the 'problem' of addiction in drug treatment. Qualitative Health Research, 23, 916-923.

Neale, J., Tompkins, C., Wheeler, C., Finch, E., Marsden, J., Mitchenson, L., . . . Strang, J. (2015). "You're all going to hate the word 'recovery' by the end of this": Service users' views of measuring addiction recovery. Drugs: Education, Prevention and Policy, 20(1), 24-26.

Radcliffe, P \& Stevens, A. (2008). Are drug treatment services only for 'thieving junkie scumbags'? Drug users and the management of stigmatised identities. Social Science \& Medicine 67(7): 1065-1073. 
Rance, J. \& Treloar, C. (2013). 'Not just Methadone Tracy': Transformations in service-user identity following the introduction of hepatitis $C$ treatment into Australian opiate substitution settings. Addiction 109(3): 452-459.

Reinarman, C. (2005). Addiction as accomplishment: The discursive construction of disease. Addiction Research \& Theory 13(4), 307-320.

Room, R. (2003). The cultural framing of addiction. Janus Head, 6(2): 221-234.

Savic, M. \& Fomiatti, R. (2016). Producing 'progress' through the implementation of outcome monitoring in alcohol and other drug treatment. Contemporary Drug Problems 43(2), 169-187.

Sedgwick, E. (1993). Epidemics of the will. In M. Barale, J, Goldberg, M. Moon \& E. Sedgwick. (eds) Tendencies (pp. 130-142). Durham: Duke University Press.

Shinebourne, P. \& Smith, J.A. (2010). The communicative power of metaphors: an analysis and interpretation of metaphors in accounts of the experience of addiction. Psychology and Psychotherapy: Theory, Research and Practice, 83, 59-73.

Smith, C.B.R. (2010). Socio-spatial stigmatization and the contested space of addiction treatment: Remapping strategies of opposition to the disorder of drugs. Social Science \& Medicine, 70(6) 859-866.

Smith, C.B.R. (2011). A Users' Guide to 'Juice Bars' and 'Liquid Handcuffs' Fluid Negotiations of Subjectivity, Space and the Substance of Methadone Treatment. Space and Culture 14(3): 291-309.

valentine, k. \& Fraser, S. (2008). Trauma, damage and pleasure: Rethinking problematic drug use. International Journal of Drug Policy, 19, 410-416.

Valverde, M. (1998). Diseases of the will: Alcohol and the dilemmas of freedom. Cambridge: Cambridge University Press.

Valverde, M. (2002). Experience and Truthtelling: Intoxicated Autobiography and Ethical Subjectivity. Outlines, 1, 3-18.

Warhol, R. \& Michie, H. (1996). Twelve-Step Teleology: Narratives of Recovery/Recovery of Narrative. In S. Smith \& J. Watson (eds). Getting a Life: 
Everyday Uses of Autobiography (pp. 327-350). Minneapolis: University of Minnesota Press

Warwick Blood, R., Williams, J. \& McCallum, K. (2003). Representation of public risk: illegal drugs in the Australian press. Media International Australia, Incorporating Culture \& Policy, 108: 82-100.

World Health Organization. (1992). The ICD-10 Classification of Diseases and Related Health Problems. Geneva: World Health Organization.

Weinberg, D. (2000). "Out there": The ecology of addiction in drug abuse treatment discourse. Social Problems, 47(4), 606-621.

Woolgar, S. \& Lezaun, J. (2013). The wrong bin bag: A turn to ontology in science and technology studies? Social Studies of Science, 43(3), 321-340. 